\title{
A case report of a young patient with multiple surgical redo interventions due to recurrent endocarditis and restenosis in coronary artery bypass grafts anastomosis
}

\author{
(D)Jozica Šikićc, ${ }^{1,2}$ \\ (DDario Gulin ${ }^{1,2 *}$, \\ (DLeon Adrović', \\ (1)Tomislav Mihaljević3 \\ 'University Hospital "Sveti \\ Duh", Zagreb, Croatia \\ 2University of Zagreb School \\ of Medicine, Zagreb, Croatia \\ ${ }^{3}$ Cleveland Clinic Main \\ Campus, Ohio, United States \\ of America
}

KEYWORDS: anastomosis, restenosis, aortic valve replacement.

CITATION: Cardiol Croat. 2018;13(5-6):193. | https://doi.org/10.15836/ccar2018.193

*ADDRESS FOR CORRESPONDENCE: Dario Gulin, Klinička bolnica "Sveti Duh“, Sv. Duh 64, HR-10000 Zagreb, Croatia. / Phone: +385-91-3713-398 / E-mail: dariogulin@gmail.com

ORCID: Jozica Šikić, https://orcid.org/0000-0003-4488-0559 • Dario Gulin, https://orcid.org/0000-0001-8502-7816 Leon Adrović, https://orcid.org/0000-0002-0555-6863 • Tomislav Mihaljević, https://orcid.org/0000-0002-8751-8149

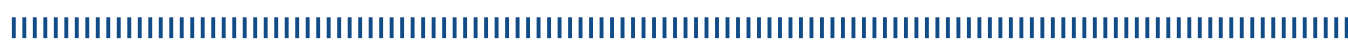

Background: So far, no percutaneous nor cardiac surgical intervention did not present with significant and apparent long-term graft patency preventing and treating coronary artery bypass graft (CABG) restenosis at the site of the anastomosis ${ }^{1}$. A process of restenosis, mainly driven by intimal hyperplasia, with abnormal migration and proliferation of smooth muscle cells, has many characteristics of inflammation like process. Proliferating tissue reaction after aortic valve replacement (AVR) at the site of coronary ostia may be due to traumatic consequence, debris embolization or edematous reaction ${ }^{2,3}$ Young patients are in undesirable position.

Case report: 34-year-old man was admitted in 2007 in a local hospital due to bicuspid aortic valve endocarditis due to Streptococcus sp "D", proceeding with biological AVR. One month after the surgery, due to recurrent endocarditis presenting with paravalvular leak and severe aortic regurgitation, reoperation was performed with the implantation of the mechanical valve. Two years later symptomatic severe paravalvular aortic regurgitation and severe mitral regurgitation due to the prolapse of the anterior cusp led to invasive diagnostic approach. Coronary angiography revealed subtotal restenosis of the left main coronary artery ostium. In September 2009, simultaneous third time redo was performed with replacement of the aortic root with the homograft, mitral valve repair with a pericardial patch of a perforation of the A2 segment, medial commissuroplasty with the insertion of Cosgrove ring, CABG with saphenous vein graft (SVG) to obtuse marginal (OM) and SVG to left anterior descending artery (LAD). Two years later, occluded anastomosis of a SVG to LAD and significant restenosis of a SVG to $\mathrm{OM}$ (both at the site of anastomosis), led to re-CABG of LAD with left internal mammary artery (LIMA) and repositioning of a SVG to OM. In 2017, coronary angiography showed significant restenosis of the LIMA-LAD graft anastomosis and SVG-OM graft.

Discussion: Young patients present with intensive immunological reaction leading to CABG anastomosis or valvular junction stenosis. This patient demonstrates not only challenges in treating endocarditis, redo interventions and complications of valvular disease per se but also impediments in coronary artery supply.

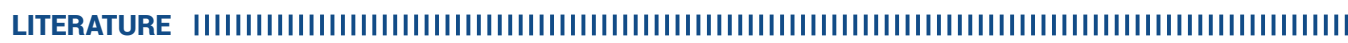

1. Jongsma H, Bekken JA, de Vries JP, Verhagen HJ, Fioole B. Drug-eluting balloon angioplasty versus uncoated balloon angioplasty in patients with femoropopliteal arterial occlusive disease. J Vasc Surg. 2016 Nov;64(5):1503-1514. https://doi.org/10.1016/j.jvs.2016.05.084

2. Bukka M, Rednam PJ, Sinha M. Drug-eluting balloon: design, technology and clinical aspects. Biomed Mater. 2018 Feb 23:13(3):032001. https://doi.org/10.1088/1748-605X/aaa0aa

3. Mavroudis CA, Kotecha T, Chehab 0 , Hudson J, Rakhit RD. Superior long term outcome associated with native vessel versus graft vessel PCI following secondary PCI in patients with prior CABG. Int J Cardiol. 2017 Feb 1;228:563-569. https://doi.org/10.1016/j.ijcard.2016.11.031 